\title{
Study on the Location of the Distribution Center of Agricultural Products
}

\author{
Mengke Chang* \\ School of Management Engineering ,Zhengzhou University, No.100 Science Avenue, Zhengzhou, China \\ cmk1589300@163.com
}

Keywords: agricultural logistics, distribution center location, gravity method, AHP

\begin{abstract}
As a large agricultural country, China regards agriculture as the basic industry of national economy, which plays a vital role in the development of the national economy. But there is a poor circulation of agricultural products, distribution center set unreasonable causes of high logistics costs. This paper introduces the related concepts of agricultural products logistics distribution center location, and describes several commonly used methods of logistics distribution center location. On the basis of these theories, the paper establishes the gravity method and AHP model. The gravity method is simple and convenient, which is the most commonly used method; AHP is qualitative and quantitative, increasing the effectiveness of decision-making. Finally, taking Zhengzhou as an example, by using two methods, namely the gravity method and AHP, this paper compares the selected Zhengzhou agricultural products logistics distribution center location, and sums up the results of the two methods to get the final result.
\end{abstract}

\section{INTRODUCTION}

In recent years, the issue of "agriculture, rural areas and farmers" has become the focus of the CPC Central Committee, Premier Jiabao Wen has put forward: "Now limit the development of domestic demand is mainly concentrated in the backward agricultural development and slow growth of farmers income." To achieve the rapid development of China's economy, Must take the means to solve this problem. During the early period of reform and opening up, the "three rural" problems mainly concentrated in the field of production, and now, with the improvement of agricultural technology, the quality of agricultural products has increased significantly, the "three rural" problem shifted to the field of agricultural products circulation. To solve the problem of "three rural", we must vigorously develop the logistics of agricultural products, ensure the smooth flow of agricultural products, reduce the cost and waste of all aspects of the problem, to create greater value, thereby promoting agricultural development, increase farmers' income, to achieve the overall Increased interest.

But the current status of China's agricultural products logistics is not optimistic. First of all, the production of agricultural products is regional and seasonal, and consumer demand for agricultural products is unrestricted, this business and the contradiction between consumers is irreconcilable, can not be avoided. Second, China's vast land, rich agricultural resources, widely distributed, how to quickly and high-quality agricultural products to the hands of consumers, which is a huge challenge. In addition, agricultural products logistics generally through the production of agricultural products, local wholesalers acquisition, dealers to buy, and then to the pin market, and then by the retailers to reach the hands of consumers. Each link of the logistics costs and agricultural products of their own characteristics of the high demand for all aspects of agricultural logistics costs lead to too high. This makes the agricultural products can not achieve the smooth flow, coupled with agricultural products easy to rot, storage difficult to the characteristics of China's agriculture caused great losses and waste. At present, the poor circulation of agricultural products has become an important negative factor restricting China's rural economy and farmers' income, and it is urgent to improve the current situation of agricultural products logistics.

The location of agricultural products distribution plays an important role in the whole agricultural logistics. Agricultural logistics distribution center is an important part of agricultural logistics, it is the organization of agricultural products stocking, storage, cargo handling, distribution, delivery as the main function of the circulation node. It is to connect the producers and consumers of the middle of the bridge, to ensure the supply of agricultural products and quality and safety plays an extremely important role. The reasonable distribution center location not only can improve the efficiency of agricultural products distribution, reduce costs, but also to promote China's agricultural and rural economic development, improve the income of farmers has important practical significance.

Based on the analysis of the location of agricultural product logistics distribution center, this paper establishes an analytical model and provides an empirical analysis to provide a basis for the development of modern agricultural logistics and distribution center.

\section{LITERATURE REVIEW}

\subsection{Status of Foreign Research}

Kannan, G. proposed a five-level supply chain network, the establishment of multi-objective optimization model, and the use of multi-objective hybrid algorithm to solve the model (Kannan, 2015). Morteza, A., in order to achieve the optimal location from the alternative address and determine the minimum cost of the target, the establishment of a mixed integer nonlinear programming model, and further use the meta-heuristic algorithm to solve the model (Morteza, 
2015). The Ronald, G. A. studied the distribution network design problem, established the mathematical model to solve the complex facility location problem, and combined with the example to solve the problem (Ronald, 2014). Seyed, M., etc., have studied the location-allocation problem with capacity constraints in the case of customer demand and location uncertainty. The distance between customers and facilities is expressed by Euclidean distance. The customer demand is assumed to be fuzzy demand, Shape algorithm, fuzzy simulation and improved genetic algorithm to solve the model (Seyed, 2013).

\subsection{Status of Domestic Research}

Although China's agricultural products logistics and distribution site started late, but in the efforts of many outstanding scholars also made a lot of results. Based on the Median-based model, Xianghua Chu constructed a distribution center location model with capacity constraints. A heterogeneous multi-group particle swarm optimization algorithm was proposed and verified by simulation experiments. And the effectiveness of convergence speed (Xianghua Chu, 2013). Weimin Di, In order to improve the performance of logistics management, considering the perishable characteristics of agricultural products and the capacity limitation of distribution center, a 0-1 integer nonlinear programming model is constructed and a hybrid genetic algorithm is proposed to embed the modified table., Given the specific implementation steps, and finally through the example to verify its effectiveness (Weimin Di, 2013). Kaifan Dong studied the problem of multi-objective distribution center location with timeliness and economy. The cost is the smallest objective function, the customer's requirement of delivery time is transformed into the model constraint condition, the distribution center location model is established, The optimization algorithm of the location problem is discussed: Sequential Quadratic Programming (SQP), which is combined with the example (Kaifan Dong, 2013).

From the above overview of the distribution center location can be seen, domestic and foreign experts and scholars in theory on things The research on the location method of the flow distribution center has been relatively mature, especially the theoretical research. Linear programming, analytic hierarchy process, genetic algorithm and so on are applied to the location model, not only qualitative analysis, quantitative research, but also a combination of qualitative and quantitative methods. And many methods are the combination of theory and practice of the product, the reality has in-depth guiding significance. This paper will draw on the experience of scholars, use the method of gravity and analytic hierarchy process to establish the model, and use examples to verify the solution.

\section{THEORIES}

There are many ways to locate the logistics distribution center, different methods have different scope of application, suitable for different situations, in the logistics and distribution center location, according to the actual situation, the location of the method to choose. In many ways, the center of gravity method is a more commonly used method, the focus of the location of the location of the selected geographical location is not a specific limit, you can choose, which is an advantage of the center of gravity method, in addition, Time, there will be a large value of transport costs, in this case with the center of gravity method of geographical location choice is very reasonable, specific to agricultural products, because of its relatively large size, weight, so the transport cost is relatively large, so Is also very suitable for this approach. But the center of gravity method has a significant drawback is that the geographical location is not restricted, so the selected address may not be realistic. The Analytic Hierarchy Process (AHP) is the best option to select the best scheme from several alternatives. It is consistent with the research on the site selection of Zhengzhou agricultural product distribution center in this paper, and selects the most suitable area for the distribution of the distribution center from several cities address. Therefore, this paper uses the center of gravity method and the analytic hierarchy process to ensure the location of the two sites to ensure the practicality of the site.

\section{METHODOLOGY}

This paper takes Zhengzhou City as an example to study the location of agricultural product logistics distribution center. Zhengzhou is the political, cultural and economic center of Henan Province, the city's total area of 7446.2 square kilometers, the resident population of 9.569 million people. Jin cheng District, Gong yi City, Deng feng City, Xing yang City, Xin mi City, Xin zheng City, Zhong mou County, the Central Plains District, the Central City District, Hui ji District, Shang jie District The Zhengzhou City, agricultural products wholesale market is mainly distributed in Jin shui District, Er qi District, Central Plains District, which Jin shui District, the largest wholesale market, a representative of about 24, two seven districts with a representative of about 13 , the Central Plains The area is representative of about 18, and the three districts have a larger population density. In order to promote the development of local economy and meet the demand of supply and marketing of agricultural products in Zhengzhou, this paper will set up a distribution center in the area of Jin shui District, Er qi District, Zhong yuan District, which is concentrated and contains more agricultural supply points.

\subsection{Distribution Center Location Based on Analytic Hierarchy Process}

In the use of analytic hierarchy process, we assume that the given value is more reasonable. 


\subsubsection{Establish a Hierarchical Model}

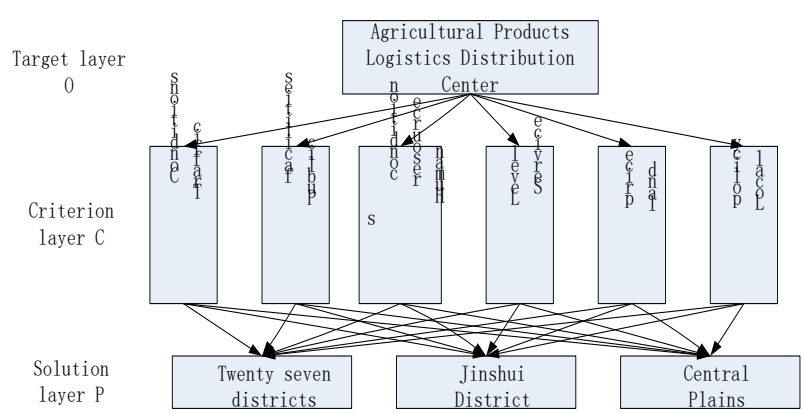

Figure 1: Hierarchical model of agricultural product logistics distribution center

\subsubsection{Constructed Pairs of Comparative Array and Consistency Test}

After consulting the relevant experts, according to the meaning of the scale, to determine the criteria of the six factors on the target layer of the distribution center of the importance of the location, so get the target layer on the target layer of the baseline judgment matrix.

Table 1: Comparison matrix of target layer and criterion layer

\begin{tabular}{|c|c|c|c|c|c|c|}
\hline & C1 & C2 & C3 & C4 & C5 & C6 \\
\hline C1 & 1 & 1 & 1 & 4 & 1 & $1 / 2$ \\
\hline C2 & 1 & 1 & 2 & 4 & 1 & $1 / 2$ \\
\hline C3 & 1 & $1 / 2$ & 1 & 5 & 3 & $1 / 2$ \\
\hline C4 & $1 / 4$ & $1 / 4$ & $1 / 5$ & 1 & $1 / 3$ & $1 / 3$ \\
\hline C5 & 1 & 1 & $1 / 3$ & 3 & 1 & 1 \\
\hline C6 & 2 & 2 & 2 & 3 & 1 & 1 \\
\hline
\end{tabular}

$\omega=(0.16,0.19,0.19,0.05,0.12,0.30) \lambda_{\max }=63$

$\mathrm{CI}=0.07 \mathrm{RI}=1.24 \mathrm{CR}=0.056<0.1$

Table 2: Judgment matrix of traffic condition C1

\begin{tabular}{|c|c|c|c|}
\hline C1 & P1 & P2 & P3 \\
\hline P1 & 1 & $1 / 3$ & $1 / 2$ \\
\hline P2 & 3 & 1 & 3 \\
\hline P3 & 2 & $1 / 3$ & 1 \\
\hline
\end{tabular}

$\omega=(0.16,0.60,0.25) \lambda_{\max }=3.05$

$\mathrm{CI}=0.03 \mathrm{RI}=0.58 \mathrm{CR}=0.046<0.1$

Table 3: Judgment matrix of public facilities C2

\begin{tabular}{|c|c|c|c|}
\hline C2 & P1 & P2 & P3 \\
\hline P1 & 1 & $1 / 4$ & 3 \\
\hline P2 & 4 & 1 & 7 \\
\hline P3 & $1 / 3$ & $1 / 7$ & 1 \\
\hline
\end{tabular}

$\omega=(0.21,0.70,0.08) \lambda_{\max }=3.03$

$\mathrm{CI}=0.016 \mathrm{RI}=0.58 \mathrm{CR}=0.028<0.1$

Table 4: Judgment Matrix of Environmental Condition C3

\begin{tabular}{|c|c|c|c|}
\hline C3 & P1 & P2 & P3 \\
\hline P1 & 1 & $1 / 3$ & $1 / 5$ \\
\hline P2 & 3 & 1 & $1 / 4$ \\
\hline P3 & 5 & 4 & 1 \\
\hline
\end{tabular}

$\omega=(0.10,0.23,0.68) \lambda_{\max }=3.08$

$\mathrm{CI}=0.04 \mathrm{RI}=0.58 \mathrm{CR}=0.074<0.1$
Table 5: Service level C4 judgment matrix

\begin{tabular}{|l|l|l|l|}
\hline C4 & P1 & P2 & P3 \\
\hline P1 & 1 & $1 / 4$ & 2 \\
\hline P2 & 4 & 1 & 7 \\
\hline P3 & $1 / 2$ & $1 / 7$ & 1 \\
\hline
\end{tabular}

$\omega=(0.19,0.72,0.10) \lambda_{\max }=3.002$

$\mathrm{CI}=0.001 \mathrm{RI}=0.58 \mathrm{CR}=0.0017<0.1$

Table 6: Judgment matrix of economy C5

\begin{tabular}{|c|c|c|c|}
\hline C5 & P1 & P2 & P3 \\
\hline P1 & 1 & 1 & 2 \\
\hline P2 & 1 & 1 & 3 \\
\hline P3 & $1 / 2$ & $1 / 3$ & 1 \\
\hline
\end{tabular}

$\omega=(0.39,0.44,0.17) \lambda_{\max }=3.018$

$\mathrm{CI}=0.009 \mathrm{RI}=0.58 \mathrm{CR}=0.016<0.1$

Table 7: Local policy C6 judgment matrix

\begin{tabular}{|c|c|c|c|}
\hline C6 & P1 & P2 & P3 \\
\hline P1 & 1 & 3 & 3 \\
\hline P2 & 3 & 1 & 2 \\
\hline P3 & $1 / 3$ & $1 / 2$ & 1 \\
\hline
\end{tabular}

$\omega=(0.60,0.24,0.16) \lambda_{\max }=3.05$

$\mathrm{CI}=0.027 \mathrm{RI}=0.58 \mathrm{CR}=0.046<0.1$

\subsubsection{Hierarchical Ranking}

Table 8: Hierarchical Ranking

\begin{tabular}{|c|c|c|c|c|c|c|c|}
\hline & C1 & C2 & C3 & C4 & C5 & C6 & total \\
\cline { 2 - 7 } & 0.16 & 0.19 & 0.19 & 0.05 & 0.12 & 0.3 & weight \\
\hline P1 & 0.16 & 0.21 & 0.1 & 0.19 & 0.39 & 0.6 & 0.32 \\
\hline P2 & 0.6 & 0.7 & 0.23 & 0.72 & 0.44 & 0.25 & 0.44 \\
\hline P3 & 0.25 & 0.08 & 0.68 & 0.1 & 0.17 & 0.16 & 0.26 \\
\hline
\end{tabular}

Because P2 score > P1 score> P3 score, it should be located in the P2 area, that is, agricultural logistics and distribution center should be selected in the Jin shui District.

\subsection{Location of Distribution Center Based on Center of Gravity Method}

Table 9: Zhengzhou agricultural products wholesale market demand unit: million tons

\begin{tabular}{|c|l|l|l|l|l|}
\hline & 2006 & 2007 & 2008 & 2009 & 2010 \\
\hline $\begin{array}{c}\text { Mao } \\
\text { zhuang } \\
\text { vegetable } \\
\text { wholesale } \\
\text { market }\end{array}$ & 20.49 & 21.92 & 23.36 & 24.92 & 26.75 \\
\hline $\begin{array}{c}\text { Liu } \\
\text { zhuang } \\
\text { vegetable } \\
\text { wholesale } \\
\text { market }\end{array}$ & 14.35 & 15.32 & 16.42 & 17.54 & 18.78 \\
\hline $\begin{array}{c}\text { Chen } \\
\text { Zhai } \\
\text { vegetable } \\
\text { wholesale } \\
\text { market }\end{array}$ & 19.94 & 20.94 & 21.99 & 23.08 & 24.24 \\
\hline
\end{tabular}

After access to information, I found that Zhengzhou City, the larger agricultural products wholesale market: Liu zhuang vegetable wholesale market, Chen zhai vegetable wholesale market, Mao zhuang vegetable 
wholesale market. The market share of the three wholesale markets accounted for about $60 \%$ of the city, and demand also showed a sustained trend, 2006-2010 demand as shown in Table 9 below.

Based on the above table data, the demand for each wholesale market in 2016 is shown in Table. 10:

Table 10: Demand in 2016 Unit: 10,000 tons

\begin{tabular}{|c|c|c|c|}
\hline & $\begin{array}{c}\text { Mao } \\
\text { zhuang } \\
\text { vegetable } \\
\text { wholesale } \\
\text { market }\end{array}$ & $\begin{array}{c}\text { Liu } \\
\text { zhuang } \\
\text { vegetable } \\
\text { wholesale } \\
\text { market }\end{array}$ & $\begin{array}{c}\text { Chen Zhai } \\
\text { vegetable } \\
\text { wholesale } \\
\text { market }\end{array}$ \\
\hline $\begin{array}{c}\text { Demand } \\
\text { in 2016 }\end{array}$ & 41.38 & 29.40 & 30.93 \\
\hline
\end{tabular}

This article intercepts some maps of Zhengzhou City, and then marked the coordinates of the three wholesale markets as shown in Table 11 below:

Table 11: Basic data on wholesale markets

\begin{tabular}{|c|c|c|c|c|}
\hline $\begin{array}{c}\text { wholesale } \\
\text { market }\end{array}$ & $\begin{array}{c}\text { Demand(ten } \\
\text { thousand } \\
\text { tons) }\end{array}$ & $\begin{array}{c}\text { Transportation } \\
\text { rate(yuan/million } \\
\text { tons * km) }\end{array}$ & $\begin{array}{c}\text { Coordinate } \\
\mathrm{X}\end{array}$ & $\begin{array}{c}\text { Coordinate } \\
\mathrm{Y}\end{array}$ \\
\hline $\begin{array}{c}\text { Mao } \\
\text { Zhuang }\end{array}$ & 41.38 & 300 & 16.78 & 45 \\
\hline $\begin{array}{c}\text { Liu } \\
\text { Zhuang }\end{array}$ & 29.40 & 300 & 27.7 & 40.2 \\
\hline $\begin{array}{c}\text { Chen } \\
\text { Zhai }\end{array}$ & 30.93 & 300 & 25.15 & 32.9 \\
\hline
\end{tabular}

Substituting the above data into the formula for solving the center of gravity method and solving it with the excel scheme. The result of the solution is: the result coordinates (24.202388, 39. 48068402) are roughly near Garden Road and San quan Road.

\subsection{Summary}

In this paper, two methods are used, namely, the analytic hierarchy process, the center of gravity method, the AHP method. The Zhengzhou agricultural product logistics distribution center should be built in Jin shui District, and the center of gravity distribution of Zhengzhou agricultural products should be built in the garden North Road, near San quan Road, and Garden Road, near the whole road belongs to Jin shui District, so that the two methods concluded that the same conclusion, with the center of gravity method of Zhengzhou agricultural products logistics and distribution center should be located in the garden North Road, near the whole road is also the specific analysis of the analytic hierarchy process.

\section{CONCLUSIONS}

In this paper, Zhengzhou City, as an example of empirical research, respectively, the use of analytic hierarchy process and the center of gravity to solve the address, showing two results consistent, and ultimately to determine the location address. Although this paper builds up the model and carries on the empirical research on the basis of the farmland logistics distribution center selection theory, the analytic hierarchy process can only draw the optimal scheme from the alternative, and the rough address can not be obtained. The There are still many uncontrollable factors, the model needs to be improved. In the future still need to do a lot of work for in-depth study.

\section{REFERENCES}

[1] Alizadeh, M. \& Mahdavi, I. \& Amiri, N. \& Shiripour, S., 2015. A capacitated location-allocation problem with stochastic demands using sub-sources: An empirical study, Applied Soft Computing. 34, pp.551-571.

[2] Askin, R. \& Baffo, I. \& Xia, M., 2014. Multi-commodity warehouse location and distribution planning with inventory consideration, International Journal of Production Research. 52(7), pp.1897-1910.

[3] Govindan, K. \& Jafarian, A. \& Nourbakhsh, V., 2015. Bi-objective integrating sustainable order allocation and sustainable supply chain network strategic design with stochastic demand using a novel robust hybrid multi-objective metaheuristic, Computers \& Operations Research. 62, pp.112-130.

[4] Kaifan, Dong \& Hongcheng, Gan, \& Huizhen, Zhang, 2013 Distribution center location model based on economics and timeless, University of Shanghai for Science and Technology. 35(4), pp.336-339.

[5] Mousavi, S. \& Niaki, S., 2013.Capacitated location allocation problem with stochastic location and fuzzy demand: A hybrid algorithm, Applied Mathematical Modelling. 37, pp.5109-5119.

[6] Weinmin, Di \& Yaoxue, Yue \& Guomin Chen, 2013. Method of site selection for perishable agricultural products distribution center with distribution capacity limitation, Computer Application Research. 30(1), pp.202-205.

[7] Xianghua, Chu \& Qiang, Liu \& Ben, Niu, 2013. Improved PSO-based algorithm for the capacitated location problem of distribution center, Computer Engineering and Applications. 49(7), pp.16-19. 